\title{
Migration of transition metals and potential for mineral carbonation during acid leaching of kimberlite mine tailings
} MAKOTO J. HONDA-MCNEIL ${ }^{1}$, KONSTANTIN VON

GUNTEN $^{1}$, DANIEL S. ALESSI ${ }^{1}$, GORDON SOUTHAM ${ }^{2}$, THOMAS JONES ${ }^{2}$, JESSICA L. HAMILTON ${ }^{3}$ AND DAVID J. PATERSON $^{3}$

${ }^{1}$ University of Alberta, Edmonton, AB, Canada ${ }^{2}$ The University of Queensland, St Lucia, QLD, Australia

${ }^{3}$ The Australian Synchrotron, Clayton, VIC, Australia

Carbonation of mafic and ultramafic rocks and mineral wastes provides a permanent way to sequester excess atmospheric $\mathrm{CO}_{2}$. Recent research has shown that this method also offers potential for transition metal recovery from mine tailings [1]. In this study, kimberlite tailings from Venetia mine (South Africa) were used for column acid leaching experiments to assess whether valuable base metals could be recovered during mineral carbonation. Tailings were treated daily with one pore volume of dilute $\mathrm{HCl}(0.04 \mathrm{M}, 0.08 \mathrm{M}$, $0.12 \mathrm{M}$ and $0.16 \mathrm{M}$ ) for 28 days.

Poorly crystalline and highly iron-rich yellow precipitates formed during the experiments both on the top of the tailings and within the leachates. The carbonation potential and mobility of transition metals were investigated with a combination of quantitative X-ray diffraction (XRD) using Rietveld refinements, inductively coupled plasma mass spectrometry (ICP-MS), scanning electron microscopy (SEM) coupled with energy-dispersive X-ray spectroscopy (EDXS) and X-ray fluorescence microscopy (XFM) coupled with micro-X-ray absorption near edge structure ( $\mu$-XANES) analyses at the Cr K-edge and Ni K-edge.

Our results show that the high proportion of clay minerals (e.g., lizardite, smectites, talc, chlorite) in the tailings act as a source for $\mathrm{Ca}, \mathrm{Mg}$ and transition metals such as $\mathrm{Fe}$. The extraction rate of $\mathrm{Mg}$ and $\mathrm{Ca}$ increases with $\mathrm{HCl}$ concentration; however, calcite is the main source for $\mathrm{Ca}$, decreasing the net $\mathrm{CO}_{2}$ sequestration potential. Clay minerals provide $\mathrm{Mg}$, accounting for an estimated $\mathrm{CO}_{2}$ offset potential ranging from $2-16 \%$ at Venetia. Release of transition metals decreases with depth in columns. Unlike $\mathrm{Ca}$ and $\mathrm{Mg}$, which are mobilized into leachates, transition metals such as $\mathrm{Ni}$ are concentrated into the yellow precipitates at the tops of columns, providing guidance for future economic recovery.

[1] Hamilton, J. L. et al., 2018, International Journal of Greenhouse Gas Control, 71, 155-167. 